
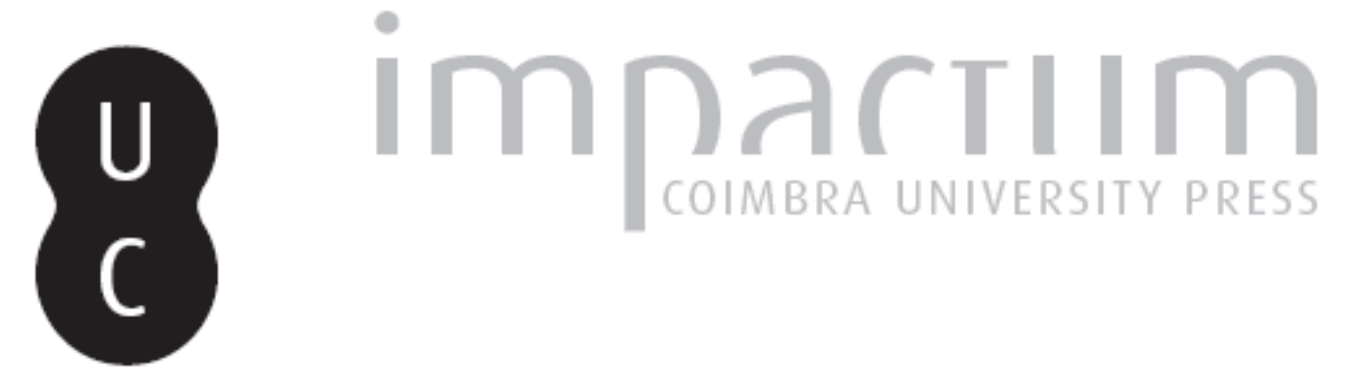

\title{
O tema da raiva na retórica e na ética de Aristóteles
}

Autor(es): Rowe, Christopher

Publicado por: Annablume Clássica; Imprensa da Universidade de Coimbra

URL persistente:

URI:http://hdl.handle.net/10316.2/24300

DOI:

DOI:http://dx.doi.org/10.14195/1984-249X_9_1

Accessed : $\quad$ 26-Apr-2023 14:52:22

A navegação consulta e descarregamento dos títulos inseridos nas Bibliotecas Digitais UC Digitalis, UC Pombalina e UC Impactum, pressupõem a aceitação plena e sem reservas dos Termos e Condições de Uso destas Bibliotecas Digitais, disponíveis em https://digitalis.uc.pt/pt-pt/termos.

Conforme exposto nos referidos Termos e Condições de Uso, o descarregamento de títulos de acesso restrito requer uma licença válida de autorização devendo o utilizador aceder ao(s) documento(s) a partir de um endereço de IP da instituição detentora da supramencionada licença.

Ao utilizador é apenas permitido o descarregamento para uso pessoal, pelo que o emprego do(s) título(s) descarregado(s) para outro fim, designadamente comercial, carece de autorização do respetivo autor ou editor da obra.

Na medida em que todas as obras da UC Digitalis se encontram protegidas pelo Código do Direito de Autor e Direitos Conexos e demais legislação aplicável, toda a cópia, parcial ou total, deste documento, nos casos em que é legalmente admitida, deverá conter ou fazer-se acompanhar por este aviso. 


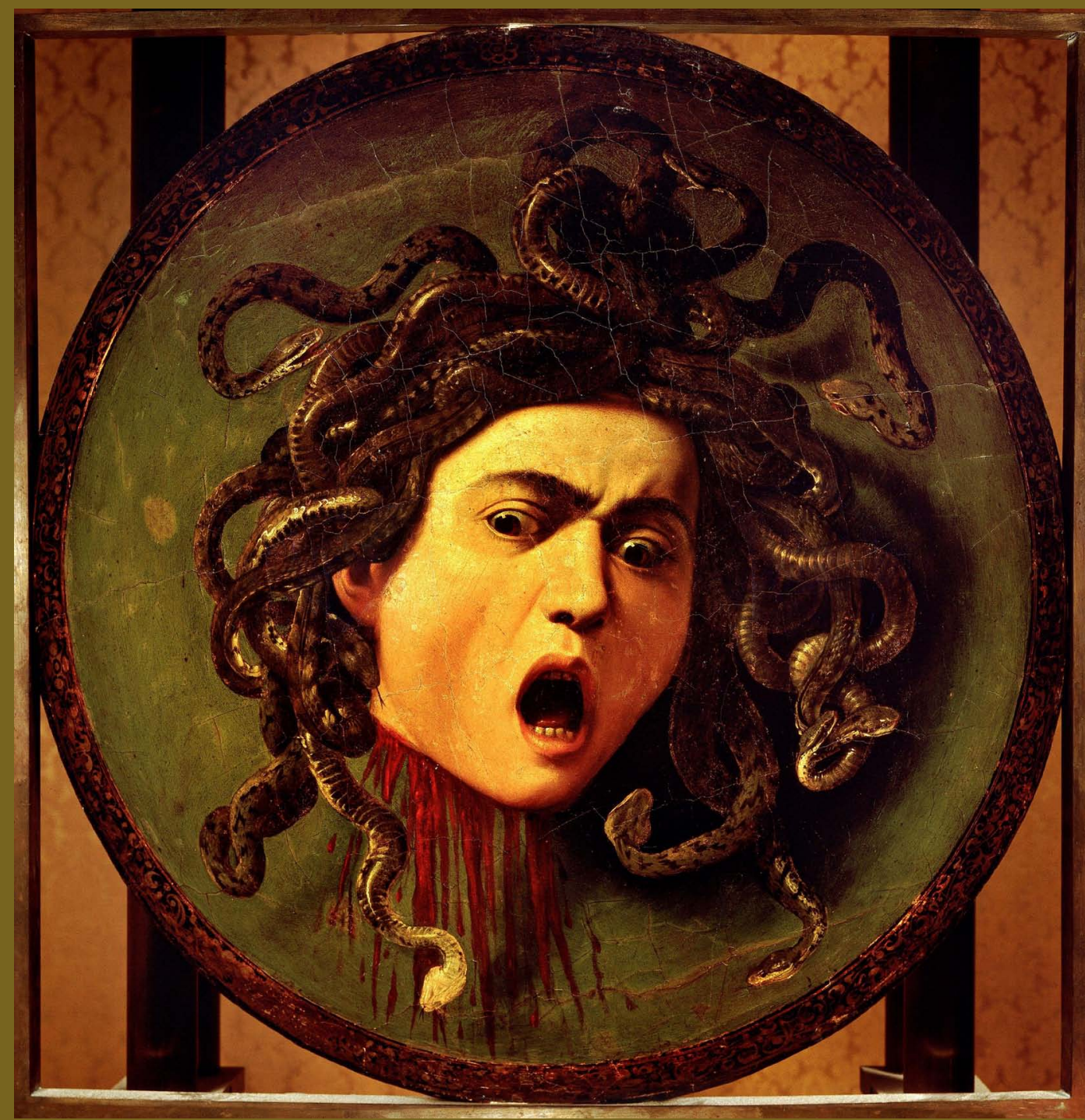

\section{R E V I S T A}
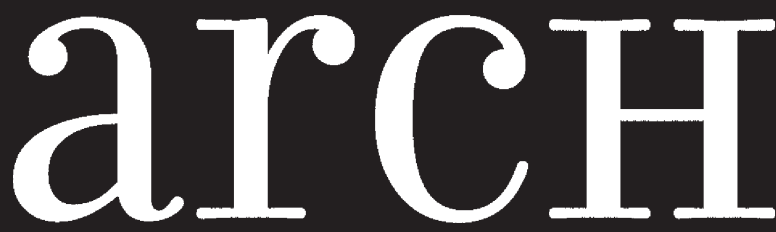
AS ORIGENS DO PENSAMENTO OCIDENTAL

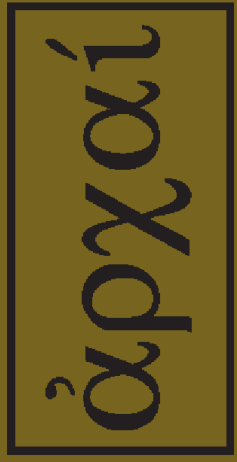

ARCHAI JOURNAL: ON THE ORIGINS OF WESTERN THOUGHT
arcHaI

arementam

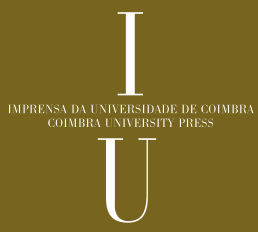

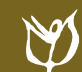

NNN 


\section{TEMA DA RAIVA NA RETÓRICA E NA ÉTICA DE ARISTÓTELES}

ROWE, C. (2012). “0 tema da raiva na Retórica e na Ética de Aristóteles". Archai n. 9, jul-dez 2012, pp. 11-16.

RESUMO: Em breve "diálogo" com dois textos do Prof. John Cooper, este artigo trata um aspecto particular da relação entre os tratamentos da "alma", principalmente, no Livro IV da República de Platão; e por Aristóteles no De anima, na Retórica e nos tratados éticos. Para Platão, a alma humana representa a combinação de três elementos, partes ou fatores - logistikon, thumoeides, epithumêtikon -, comparáveis a um homem, um leão e um monstro e respectivamente associados a ações causadas pela razão, pelo "thumos" ou por nossos apetites. A tripartição é uma ideia dominante pelo menos em contextos relacionados à psicologia moral e à explicação da ação nos diálogos platônicos a partir da República. Não há grande interesse de Aristóteles pelas "partes" da alma, mas pelo menos no contexto ético há alguma tendência a dividir a alma, se bem que apenas por analogia, e divide frequentemente o desejo em três subtipos - boulêsis, thumos e epithumia. Contudo, naqueles textos aristotélicos que se preocupam mais diretamente com a psicologia moral, isto é, os tratados éticos e a Retórica, o que realmente mais chama a atenção é, acima de tudo, a ausência da tripartição da alma. Para Aristóteles, não há muita utilidade para qualquer ideia de "partes" da alma no sentido platônico.

PALAVRAS-CHAVE: Tripartição da alma, thumos (thymos), thumoeides (thymoeides), boulêsis, orgê.

ABSTRAC: In "discussion" with two texts from Prof. John Cooper, this paper covers a particular aspect of the relation between the treatments of the soul by Plato in the Republic, especially
Christopher Rowe*

\section{Introdução}

Departament of Classics and Ancient History da Durham University, Reino Unido.E-mail: c.j.rowe@ durham.ac.uk . 0 presente artigo foi originalmente apresentado no Fourth International Symposium on Aristotelian Philosophy, organizado pela Society for Aristotelian Studies ("The Lyceum") em Atenas, em 2002, e publicado por ela

em inglês, no resultante

volume, intitulado 0 n Aristotle's Poetics and the Art of Rhetoric (Atenas, 2003). Agradeço ao editor, Professor D. Koutras, e à Society, pela permissão de vê-lo traduzido essencialmente em sua forma original. Uma versão italiana ligeiramente modificada, "La trattazione dell'ira nella Retorica e nelle Etiche di Aristotele", foi apresentada em uma conferência em Pádua em 2008; modificações ulteriores foram feitas em janeiro de 2011.
Este breve artigo debate um aspecto particular da relação entre as abordagens da alma por Aristóteles e Platão. Deve ser útil, contudo, começar por um delineamento daquilo que eu tomo por serem os contornos gerais desses tratamentos (o de Platão conforme desenvolvido especialmente no Livro IV da República; o de Aristóteles conforme oferecido no De anima assim como na Retórica e nos tratados éticos):

A. Para Platão, ao menos em algumas partes da República ${ }^{1}$ a alma humana representa a combinação de três elementos ou fatores, cada qual pode ser comparado, respectivamente, a um homem, um leão e um monstro. Cada um desses elementos ou fatores - Sócrates na República também os denomina "partes", mas geralmente usa outros termos ou circunlocuções - vem traçados pelos seus próprios desejos, que podem direta ou indiretamente fazer uma pessoa agir; assim, existem ações causadas pela razão, ações causadas por nosso aspecto "thumoeidico" ou “dotado de espírito (spirited)" e ações causadas por nossos apetites. Para Aristóteles, ao contrário, é como se o "guarda do zoológico" (o homem, no modelo de Platão) se fundisse com 
in Book IV, and by Aristotle in De anima, the Rhetoric and the ethical treatises. For Plato, the human soul represents the combination of three elements, parts or factors - logistikon, thumoeides, epithumêtikon -, comparable to a man, a lion and a monster, and respectively associated to actions caused by reason, by "thumos" or by our appetites. Tripartition is a dominant idea at least in contexts related to moral psychology and to the explanation of action in Plato's dialogues from the Republic onwards. Aristotle is not so much interested in the "parts" of the soul but, at least in the ethical context, has some tendency to divide the soul, although only by analogy, and frequently divides desire in three sub-kinds - boulêsis, thumos, epithumia. However, in those Aristotelian texts that are most directly concerned with moral psychology, i.e. the ethical treatises and the Rhetoric, it is actually the absence of the soul's tripartition that is, overall, most noticeable. For Aristotle, ultimately there is little use for any idea of "parts" of the soul in the Platonic sense.

KEY-WORDS: Soul's tripartition, thumos (thymos), thumoeides (thymoeides), boulêsis, orgê.

suas mutações (leão e monstro). Aristóteles não se interessa tanto pelas "partes" da alma, mas por seus tipos: a alma é analisada em suas faculdades, em cada faculdade superior pressupondo aquelas abaixo dela, e com a presença da razão, nos seres humanos, realçando os desejos e as capacidades daquilo que Platão tendia a tratar como essencialmente sub-humano (o leonino e o monstruoso). 0 racional e o irracional, para Aristóteles, devem trabalhar juntos, se a ação tiver seu lugar no todo.

B. 0 novo modelo de Aristóteles é o que torna possivel o tipo de abordagem da educação que ele advoga, por meio da retórica e do drama ou poesia. 0 modelo nos fornece uma visão essencialmente humanista dos indivíduos na assembléia, no tribunal e no teatro, permitindo que a emoção e o desejo sejam direcionados e informados pela razão. 0 irracional em nós pode conformar-se à razão; nós podemos como que dialogar com ele. Platão tem mais dificuldade em mostrar exatamente como a razão irá lidar, como ele precisa que ela lide, com aspectos de nós que carecem desse ingrediente (a razão). Como, racionalmente, poderíamos nos pegar falando só com leões, ou só com monstros?

C. Postulo que Aristóteles tem alguma tendência a dividir a alma, ao menos no contexto ético, na medida em que ele distingue impulsos distintos em direção ao bem, por um lado, e ao prazer, por outro. Nossas ações geralmente têm por meta aquilo que é bom para nós, ou pelo menos aquilo que a nós parece ser bom - que pode ser algo que algum de nós acha prazeroso ou atrativo, mas que não o é para a pessoa na condição correta; essa pessoa buscará aquilo que é "bom e satisfatório" (kalon), i. e., bom enquanto admirável, e não o que é meramente bom enquanto prazeroso, embora o "satisfatório" por si mesmo também seja agradável. Como Aristóteles expõe no início de sua discussão da philia tanto na Ética a Eudemo quanto na Ética a Nicômaco $[E N]$, existem dois objetos fundamentais do "amor" (ou desejo): o bom e o prazeroso. Isso nos deixa com algo análogo à "partição" platônica da alma. Mas, e por razões que deverei mencionar brevemente, desejo argumentar que isso não é mais que uma analogia; continua sendo verdade que, ao fim, para Aristóteles não há muita utilidade para qualquer idéia de "partes" da alma no sentido platônico.

\section{A raiva na Retórica e na Ética de Aristóteles.}

As origens da seguinte e principal sessão deste artigo se encontram num encontro que tive alguns anos atrás com o Professor John Cooper, de Princeton, quando o Prof. Cooper, enquanto discutíamos (como me recordo), arriscou a sugestão de que Aristóteles teria advogado uma divisão tripartite da alma como Platão, isto é, em racional, "dotada de espírito" e apetitiva (logistikon, thumoeides, epithumêtikon). Isso, de qualquer forma, foi o que pensei que Cooper estava sugerindo, e já que isso de certo modo me causou surpresa (apesar de não a outros, segundo recordo), prometi a mim mesmo que na ocasião oportuna me aprofundaria nessas questões. 0 presente trabalho
1. Digo "algumas partes da República" porque em outras (Livro I, Livros V-VII e partes do $X)$ predomina uma descrição bem diferente da alma, uma em que não há conflito e não há partes para conflito. Discuto essa outra forma de psicologia platônica, que acredito ser mais fundamental, em outro lugar, em especial no meu livro Plato and the Art of Philosophical Writing (Cambridge, 2007), capítulos 3-5. Por que exatamente Platão permite que os dois tratamentos da alma residam lado a lado no mesmo trabalho é uma questão difícil, mas, de qualquer forma isso está além do escopo do presente artigo.

2. Devemos notar, contudo, que o próprio Aristóteles falha em dar uma explicação clara da relação entre o racional e o irracional; dizer apenas, como ele diz, que o irracional, ou um aspecto dele, é potencialmente "obediente à" razão, obviamente não nos leva muito longe. 
3. Nota dos tradutores: "deliberação", "impulsividade" e "apetite" são significados que oferecemos para palavras que 0 autor, aqui, deixa sem tradução.

4. Cooper vê Magna Moralia como uma obra genuína de Aristóteles; de qualquer maneira, não está fora do padrão, para a discussão em questão, em relação a outros trabalhos aristotélicos

indubitavelmente genuínos.

5. Nota dos tradutores: oferecemos este significado para a palavra lupê, que o autor deix sem tradução. Outras traduções possiveis são "aflição" e "dor".

6. Os "outros escritos" citado são De An. 414b2, MM 1187b37 ("sobre o thumos"), e ("para orge como um caso especial de thumosdesejo"), De An. (I.1) 403a30 Top. (VIII.1) 156a32, "com Top. 126a8-10 e (II.7) 113b1".

7. Em minha leitura, nenhuma das três passagens que Cooper cita como se mostrassem Aristóteles "atribui[ndo boulêsis] à razão mesma" (De An. 432b5, 433a23-5; Top. IV 5, 126a13) precisa ser entendida dess forma. Uma forte motivação para não supor que a boulêsis é atribuída à razão certamente é fornecida, por exemplo, pelo fato de que ela pode ser direcionada aos objetos errados; se a boulêsis "pertencesse" em qualquer sentido, exceto naquele muitíssimo fraco, à razão, então

isso aparentemente levaria própria razão a desejar coisas que nenhuma pessoa racional (aristotélica) desejaria. Ou, se isso não for obstáculo suficiente: não é uma parte essencial da teoria ética aristotélica que nosso caráter depende de maneira crucial da educação de nossos aspectos não racionais, e que a qualidade daquilo que desejamos (racionalmente) concordará com a qualidade dessa educação? Mas, se a boulêsis pertencesse à razão (novamente, em qualquer sentido, exceto naquele muitíssimo fraco) então a educação poderia ser direcionada exclusivamente à própria razão. (Admito, contudo, que talvez eu tenha falhado em compreender adequadamente aquilo que Cooper de fato quis dizer por "atribuir" boulêsis à razão) é uma concretização tardia dessa promessa que fiz a mim mesmo.

Declarações mais precisas do ponto de vista do Professor Cooper podem ser encontradas em seu ensaio "Plato's Theory of Human Motivation" (1984) e em "An Aristotelian Theory of the Emotions" (1996). Por um lado:

Aristóteles (E[thica] N[icomachea] I 13, II 5-6), descreve a virtude do caráter simplesmente como a coordenação apropriada entre a razão, de um lado, e do desejo não-racional, do outro lado. Ele não diz nada nesse contexto sobre quaisquer diferenças que possam existir em tipos de desejo não-racional. Em outras partes de sua teoria ética, porém, Aristóteles de fato preserva as distinções que levaram Platão a afirmar que a alma humana possui três partes. Ele regularmente divide orexis (o desejo) dentro de três subtipos, boulêsis ["deliberação"], thumos ["impulsividade"] e epithumia ["apetite"] (veja De An[ima] II 3, 414b2, III 9, 432b3-7; de Motu 6, 700b22; E[thica] E[udemea] II 7, 1223a26-7, 10, 1225b25-6; M[agna] M[oralia] I 12, 1187b36-7) ${ }^{4}$, e ele atribuindo o primeiro à razão em si (De An. 432b5, 433a23-5; Top [ica] IV 5, 126a13), faz com que os últimos dois pertençam ao "elemento não racional" (De An. 432b6). Assim, Aristóteles sustenta (com Platão) que a razão tem um tipo especial de desejos próprios, e ele divide os desejos não-racionais nas mesmas duas espécies que Platão reconheceu. (...) A aceitação da teoria platônica, por Aristóteles, de que existem três tipos distintos de desejo tem efeitos importantes, embora frequentemente pouco valorizados, sobre sua psicologia moral (COOPER, 1984, p. 18-19).

Em seu ensaio de 1996, Cooper adiciona a Retórica à lista dos trabalhos de Aristóteles que reconhecem essa divisão tríplice do desejo, embora a ênfase aqui seja um tanto diferente:

Pelo que já vimos, é bastante claro o que faz da raiva não apenas um desejo, mas uma emoção, de acordo com Aristóteles. Por ser acompanhada por lupê ["perturbação"] ${ }^{5}$, a raiva é um desejo perturbador e agitado por vingança; a pessoa com raiva fica transtornada por ter sido tratada com aparente desrespeito e desinteresse. Em outras palavras, não é um desejo sereno e "racional", um desejo judiciosamente pensado para infligir dor ou outra punição. Na Retórica I.10.1369a1-4, Aristóteles usa o termo "raiva" (orgê) para designar um dos três tipos de desejo que ele distingue (os outros dois sendo a vontade e o apetite). Isso implicaria que o tipo de desejo ao qual a raiva pertence, pela definição encontrada na Retórica, seria por natureza agitado e perturbador. Em outros escritos ${ }^{6}$, contudo, Aristóteles regularmente diferenciar raiva de desejo dotado de "espirito" (thumos), usando esse último termo para nomear seu segundo tipo de desejo e tratando a raiva como um caso especial seu, o caso em que o desejo é extremamente agitado e perturbado (COOPER, 1996, p. 249-50).

Em suma, a raiva é um pathos, mas é também uma espécie, e na verdade, uma subespécie de desejo, sendo a espécie em si o thumos. E o thumos, como uma espécie de desejo, é uma das três forças motivadoras da alma humana, sendo as outras duas o desejo racional e o apetitivo. Se o desejo racional pertence à razão, como Cooper evidentemente sustenta, então temos efetivamente algo bem parecido com a alma tripartite encontrada na República de Platão.

Existem, penso, poucas razões para aceitar, e bem mais razões para rejeitar, a visão que Cooper tem da razão em Aristóteles como possuidora de desejos próprios ("razão" significa aqui, a meu ver, "a [parte] que tem a razão" no sentido primário: $E N$ I.13.) Se rejeitamos essa parte da visão de Cooper, então o paralelo com Platão já fica seriamente ameaçado. Contudo, a forma como Aristóteles concebe a razão e seu relacionamento com o desejo não é uma de minhas preocupações atuais; meu objetivo aqui no presente artigo é apenas tentar esclarecer seu tratamento da raiva, i. e. de orgê e de thumos. 0 que então está em questão aqui? 0 ponto importante, suponho, diz respeito ao número de tipos fundamentais de motivação que Aristóteles reconhece. Platão, ao menos em partes da República (e alhures), reconhece três: razão, "espírito" (thumos) e apetite, não sendo o segundo redutível ao terceiro: citando Cooper mais uma vez, "[n]a teoria tripartite de Platão, (...) a competitividade e o desejo por estima e auto-estima [que, conforme argumenta Cooper, são a essência da noção platônica de thumos 
ou thumoeides $]^{8}$ são uma forma inata de motivação humana, distinta dos apetites e da razão em si e tão básica quanto estes para a natureza humana" (1984, p. 17). Cooper argumenta fortemente contra aqueles que, como Terry Penner, subestimam a importância da parte "dotada de espírito" (COOPER, 1984$, p. 4$)^{9}$ : de acordo com Cooper, ela não somente é crucial para a concepção de natureza humana de Platão e dos gregos ${ }^{10}$, mas ela deveria na verdade fazer parte de qualquer concepção moderna decente da natureza humana. “Certamente não há como negar que esse tipo de motivação, em suas diversas apresentações, desempenha um enorme papel na conduta de qualquer ser humano. Qualquer teoria plausível da motivação humana deve certamente prestar uma atenção especial a isso" (COOPER, 1984, p. 4). Se Aristóteles possuía algo como uma "teoria tripartite da alma", como aquela de Platão, isso seria seu ponto essencial: identificar as forças básicas que motivam os seres humanos a agir. Aristóteles reconhece [entre essas forças] a razão e o desejo racional (como quer que se interprete isso); ele reconhece a existência do apetite, que ele tipicamente considera como tendo o "prazeroso" como seu objeto ${ }^{11}$. Será que ele reconhece tipicamente a presença de um impulso fundamental em nós que é caracterizado pela "competitividade e o desejo por estima e auto- estima" (descrição de Cooper)?

Não há como negar que Aristóteles divide frequentemente o desejo em três espécies: boulêsis, thumos, e epithumia. Para os propósitos da presente discussão devo supor que boulêsis, ou o "desejo racional" seja, simples ou primariamente, o desejo que foi informado pelas operações da razão, ou delas deriva delas, ou ainda é meramente consistente com as mesmas. (Digo, "ou primariamente", digo justamente apenas, porque pode haver alguns desejos, como o desejo universal de saber, anunciado notoriamente como no começo da Metafísica, que será difícil associar a qualquer parte não-racional. Assim, deve ser dito que aquele desejo deve pertencer à parte racional; isso abre o caminho para a visão de Cooper de que a parte racional em geral deve ser entendida como possuidora de seus próprios desejos. Eu deveria querer resistir a essa inferência, admitindo ao mesmo tempo que a forma de "desejo racional" em questão deve ser difícil de encaixar na divisão aristotélica tripartite de orexis.) 0 ponto sobejamente predominante que extraímos das Éticas - tanto da Nicomaquéia quanto da Eudêmia - é o da razão trabalhando com os desejos, ou fracassando em trabalhar com eles. Mas, se isso acontece, então a divisão tripartite de desejos é plausivelmente, e de modo incontroverso, também uma divisão bipartite: desejos são racionais ou irracionais, e dá-se que os desejos irracionais são subsumidos, ou podem ser vistos como subsumíveis, a duas formas básicas, "thumoeidico" e apetitivo. Como tenho sugerido esse tipo de divisão de fato já implica em uma divergência considerável em relação ao Platão da República, isto é, se os "desejos racionais" não são realmente desejos da "parte racional", to logon echon (no sentido primário), ou, expondo isso de forma mais transparente, se a avaliação, o raciocínio e assim por diante forem pensados como funções essencialmente separadas do desejar, em todas ou em qualquer uma de suas formas. E isso faz com que talvez seja apropriado falar não tanto de uma manutenção por Aristóteles da descrição tripartite da alma de Platão, mas, (tomando emprestada a frase de Striker) de uma "psicologia platônica" existindo como "pano de fundo" do pensamento aristotélico (STRIKER, 1996, p. 189).

De fato, questões podem ser levantadas ${ }^{12}$ sobre o quanto o próprio Platão permaneceu comprometido com sua divisão tripartite (de forma que qualquer descrição geral sua como “a psicologia platônica" seria, a esse propósito, controversa). A República IV, talvez, seja o texto em que se localiza a ideia de tripartição, por conter o argumento básico a seu favor; o Fedro fornece dela uma expressão gráfica na estória do cocheiro da alma, enquanto Timeu o incorpora no seu relato sobre a natureza humana no Timeu. E novamente, a última parte do Político divide os seres humanos em dois tipos, ambos podendo plausivelmente serem vistos como centrados no thumoeides: um tipo é competitivo e agressivo, o outro é pacífico e não agressivo. Mas não se pode dizer que o "espírito" e a "posse do espírito" sejam centrais nas Leis, o que (se pensamos essas ideias como sendo quintessencialmente platônicas) é surpreendente à luz da extensão em que esse diálogo
8. Nota do autor.

9. Veja Penner, "Thought and Desire in Plato", em G. Vlastos (ed.), Plato II (Nova Iorque, 1971), pp. 111-13.

10. Veja a esplêndida arguição de Angela Hobbs, Plato and the Hero: Courage, Manliness and the Impersonal Good, Cambridge, 2000.

11. Isto é, o prazeroso enquanto especialmente separado de qualquer consideração do que seria kalon, ou louvável: veja §1 acima, e cf. e. g. Striker, 1996, p. 190.

12. Como de fato eu mesmo fiz: veja a nota 1 acima. 
diz respeito ao treinamento "moral": a ameaça dos apetites, em qualquer medida, parece ser levada mais a sério que qualquer potencial função, negativa ou positiva, para o thumos na cidade de Magnesia. Seja como for, claramente pode-se afirmar que a tripartição é uma ideia dominante pelo menos em contextos relacionados à psicologia moral e à explicação da ação nos diálogos platônicos a partir da República. Contudo, me impressiona quão pouca influência essa "psicologia platônica" parece ter exercido sobre os escritos de Aristóteles nesses mesmos contextos. Naqueles textos que se preocupam mais diretamente com a psicologia moral, isto é, os tratados éticos e a Retórica, o que realmente é mais perceptível, acima de tudo, a ausência da tripartição.

Começo pelos tratados éticos ou, mais precisamente (já que este artigo foi escrito com a intenção de estabelecer uma discussão, e não busca ser um tratamento abrangente do tema em questão) pela Ética a Nicômaco - adotando uma pausa apenas para notar que provavelmente não existe um contraste real entre essa obra e a Ética a Eudemo: se a última assimila a divisão tripartite do desejo numa extensão

13. Desse modo, e. g., em III 2 ou em VII 3, 1147a15.

14. John Cooper fornece uma lista na primeira das duas passagens estendidas que acima citei a partir dele. Na própria Ética Nicomaquéia, a lista completa dos três tipos de desejo aparece de fato (eu creio) somente uma vez, isto é, em III 2, 1111b11 ss., com referência às opiniões de outros.

15. Não menos por causa do desejo pela honra (que pertence à thumoeides de Platão) se mencionado separadamente.

15. Não menos por causa do desejo pela honra (que pertence à thumoeides de Platão) ser mencionado separadamente.

16. Cf. VII 6, Retórica I 10

17. Nota do autor.

18. Nota dos tradutores: Rowe emprega aqui "wish" para traduzir boúlêsis.

19. Nota dos tradutores: Rowe referiu tomar por base a tradução

de J. H. Freese (Loeb Classical Library), com modificações. maior que a anterior, ainda existem muitas ocasiões em que a própria Nicomaquéia pressupõe uma divisão do desejo irracional em thumos e epithumia ${ }^{13}$. Considerando também o número de referências a esse tipo de divisão em outros trabalhos ${ }^{14}$, devemos provavelmente pensar nessa divisão como algo que sempre esteve à disposição de Aristóteles, mas que nem sempre ele achou útil. Na Ética a Nicomaquéia, ela geralmente parece estar "na retaguarda", mas não é realmente utilizada de nenhuma maneira particularmente construtiva. De fato, o que me parece notável é o modo como, quando devemos esperar que ela seja usada, ela é realmente "deixada na prateleira". Tomemos por exemplo o tratamento da akrasia no Livro VII, ou (como ela é tradicionalmente traduzida em inglês) a "fraqueza de vontade" (weakness of will), que é onde a oposição entre diferentes tipos de motivação parece estar mais em discussão: por um lado, Aristóteles reconhece um tipo específico de akrasia que se relaciona ao thumos (VII 6); por outro lado, essa é somente a akrasia kata metaphoran (VII 5, 1149a22-4), como a akrasia ligada a dinheiro, lucro ou honra (VII 4, 1147b33-4). Se o thumos estivesse sendo considerado como uma das forças básicas em operação na alma humana, no lado irracional, então talvez se pudesse esperar que a akrasia thumou fosse tratada exatamente nas mesmas condições, e recebendo a mesma proeminência, que a akrasia no sentido "apropriado" (haplôs), isto é, a akrasia referindo-se aos apetites. $0 u$, se é o caso apenas de Aristóteles tratar o thumos aqui como sinônimo de orgê, então isso é impressionante por si só: a oposição básica à razão no esquema aristotélico provém dos apetites, dos desejos irracionais - entre os quais o thumos evidentemente é considerado como pertencente. Isso tudo certamente está implicado na lista de tipos qualificados de akrasia em 1147b33-4: alguém pode ser/estar "akraticamente" inclinado para o dinheiro, o lucro, a honra - e para o thumos, que, nesse contexto ${ }^{15}$ certamente tem o sentido específico de raiva, e ao desejo por vingança ${ }^{16}$.

Essa, apesar da referência à divisão tripartite “padrão" dos desejos na Retórica I 10, parece ser a posição geral de Aristóteles na Retórica, isto é, associar a raiva com todos os outros aspectos do irracional em nós. Dado o que Aristóteles realmente diz em I 10, isso é, ao menos em parte, inesperado:

Todas as ações humanas são o resultado dos esforços do homem ou não. Quando não, algumas acontecem por acaso e outras por necessidade. Daquelas devidas à necessidade, algumas são atribuídas à compulsão, outras à natureza (...) Daquelas coisas os homens fazem por si mesmos e de que são causa, algumas resultam do hábito, outras do desejo (orexis), e destas últimas algumas se devem ao racional [logistikos: "baseadas no cálculo"?] ${ }^{17}$ e outras ao desejo irracional. Agora, o querer $^{18}$ é um desejo pelo bem, pois ninguém quer algo a não ser que pense que é bom; [por sua vez,] os desejos irracionais são a raiva (orgê) e o apetite. Assim, todas as ações dos homens devem necessariamente se ligar a sete causas: acaso, natureza, compulsão, hábito, razão, raiva (thumos) e apetite (1368b32-1369a7) ${ }^{19}$.

A raiva (orgê), por outro lado, é tratada como sendo apenas uma espécie de desejo irracional, mas por outro lado é realmente diferenciada dos outros desejos irracionais - e a mudança lexical de orgê para 
thumos, junto com a elevação de orgê/thumos ao status de uma das causas fundamentais do comportamento humano, imediatamente leva à mente, uma vez mais, a tripartição platônica e tudo que ela implica. Mas, até onde posso ver, praticamente não nos é dado qualquer encorajamento ulterior para que pensemos nesses termos: ou a raiva é tratada como uma espécie de desejo (por vingança) $)^{20}$ ou como apenas uma das pathê - e que Aristóteles não vê contradição entre essas duas descrições (por que ele deveria?) se demonstra pelo fato de em I 10 ele se refere explicitamente ao tratamento da orgê em II 2, "na discussão das pathê" (1369b15).

Dado que a Retórica necessariamente se preocupa muito mais com questões sobre como os seres humanos funcionam - se de fato a meta é, ao menos em parte, habilitar os ouvintes de Aristóteles a entender como as platéias podem ser induzidas a mudar suas crenças e atitudes - então, é certamente impressionante que ele tenha tão pouco a dizer sobre a parte ou aspecto dos seres humanos "dotada(o) de espírito". Ou ainda, seria impressionante se ele pensasse - como faz Cooper, e como Platão possivelmente o $\mathrm{fez}^{21}$, no tempo em que escreveu a República e outros diálogos - que "a competitividade e o desejo por auto-estima" (se estes dependerem das partes "dotadas de espírito") fossem "uma forma inata de motivação humana, distinta dos apetites e da razão em si e igualmente básica como aqueles são para a natureza humana" ${ }^{\prime 22}$ Um lugar em que surge a necessidade de uma pessoa do tipo thumoeidês, ou ao menos de traços "thumoeídicos", é, significativamente, na Política, isto é, em VII 7, 1327 b36 e ss. - com uma real e inconfundível referência à República de Platão. Será que Aristóteles, na maior parte [do tempo], simplesmente não vê qualquer necessidade em tratar dos aspectos thumoeídicos da natureza humana como uma categoria separada, fazendo par com a razão e o apetite? Quando se trata dos tipos de desejo, então, certamente orgê e thumos devem ser tratados separadamente: 0 desejo por vingança (e o que pode isso implicar para atitudes direcionadas à auto-estima, e assim por diante?) parece algo diferente de outros tipos de desejos, talvez menos complicados, como a fome e a sede; mas, considerando tudo, todos os aspectos relevantes aparecerão sob diferentes aretai ("virtudes", "excelências"), e estarão sujeitos à análise dominante nos termos das oposições entre razão e não- -razão, pensamento e desejo. Contudo, penso que nesse ponto existe também uma diferença significativa entre Aristóteles e Platão. Platão articulou bastante a favor de uma suposta afinidade natural entre thumos e razão. Aristóteles está preparado para aceitar, no máximo, que o thumos "segue a razão de certo modo" (EN VII $6,1149 \mathrm{~b} 1)$; mas, o mesmo será verdade para todas as pathê, como fica particularmente claro na Retórica sendo esse aspecto, se há algum, que as distingue dos apetites. Se é verdade que “qualquer teoria plausível da motivação humana deve certamente prestar atenção especial ao [nosso aspecto 'thumoeídico']" (Cooper, mais uma vez), então haverá um sentido claro no qual a teoria propriamente aristotélica da motivação deve ser considerada implausível. De minha parte, pelo menos neste momento ${ }^{23}$, a premissa parece duvidosa. $\mathrm{Ou}$, de outra maneira, Aristóteles prestou uma "atenção especial" suficiente ao aspecto "dotado de espírito", em outras circunstâncias (under other heads) - pois John Cooper perceptivelmente não chega a dizer que uma teoria decente deveria tratá-lo, como faz Platão, como uma "parte" fundamental (uma de três?) da mente humana. "Esse tipo de motivação" certamente "tem um papel muito grande na conduta de qualquer ser humano", ou pelo menos da maioria dos seres humanos, ou de muitos deles; tratar isso como "inato", ou mesmo como inevitável, dificilmente parece inevitável, ou particularmente útil.

Tradução: Bia Batista e Edrisi Fernandes

\section{REFERÊNCIAS BIBLIOGRÁFICAS}

COOPER, John (1984). "Plato's Theory of Human Motivation". History of Philosophy Quarterly, 1, p. 3-21.

COOPER, John (1996). "An Aristotelian Theory of the Emotions". Em: A. 0. Rorty (ed.), Essays on Aristotle's Rhetoric. Berkeley: University of California Press, p. 238-57.

STRIKER, Gisela (1996), “Emotions in Context: Aristotle's Treatment of the Passions in the Rhetoric and his Moral Psychology". Em: A. 0. Rorty (ed.), Essays on Aristotle's Rhetoric. Berkeley: University of California Press, p. 286-302.

Recebido em desembro de 2011. Aprovado em janeiro de 2012.
20. Assim, mais tardiamente, de thumos e orgê, no cap.10, em $1369 \mathrm{~b} 11$.

21. Embora eu esteja inclinado a duvidar disso (como ele poderia supor que tal fato seja inato a todos nós, se ele também permanece comprometido, de alguma forma, com um modelo de psicologia humana que realmente remove esse fator de todo o contexto? [veja a nota 1 acima]).

22. Uma possibilidade que pode, em princípio, merecer consideração é que todas as pathê deveriam ser tratadas como pertencentes à thumoeides - de modo a nos dar algum tipo de distinção entre emoções, de um lado, e (primariamente?) apetites/ desejos fisiológicos de outro: $\mathrm{cf}$. Stephen R. Leighton, "Aristotle on the Emotions", em Rorty, 1996, pp. 206-37. Fatalmente, contudo, algumas das pathê parecem bastante afastadas, ou mesmo incompatíveis, em relação à competitividade e à pulsão por "estima" do tipo que se procura no philotimos de Platão. Não há certamente muito espaço, por exemplo, para a piedade.

23. Um "momento" que, em 2011, completa quase uma década; a premissa me parece ainda mais duvidosa agora do que me pareceu no outono de 2001, quando comecei a compor este artigo. 